was obliged at one time to occlude the orifice externally, so that this act could be performed easily.

I used no dressing or packing, and I studied the patient to see whether in swallowing there is an actual dilatation of the esophagus or whether it is simply opened like a bag and the food pushed downward. Before the wound closed we were able to see that in swallowing, the esophagus did not dilate to receive the food. My patient does not wear a tracheotomy tube. He wore one for some time, but happened to forget it one day, and finding that he did not need it, has dispensed with its use.

Dr. MackenziE - In the debate on malignant disease of the larynx at the Baltimore meeting of the American Laryngological Association, in 1890, I stood alone among my fellow-laryngologists, as I stand alone today, in advocacy of radical operation and by radical operation I mean total extirpation of the larynx with its lymphatics and lymphatic glands, as the only rational method of dealing with this too of ten fatal malady. Extirpation of the larynx was then, as it is now, denounced as an unjustifiable and ghastly procedure, and we are told that the operation should be abandoned because in malignant disease it has resulted in failure and that life has been shortened thereby. Even if this doubtful assertion be true, better a shorter life of comparative comfort than a prolonged life of hopeless agony. We are, however, dealing not with the past of this operation, but with its future. To the modern surgeon they are sufficiently apparent, but I believe there is one thing that the records of the future will show, namely, the reason so many cases have terminated in failure and death is because the disease has not been radically dealt with. As long as we have lymphatics to carry infection and glands to become infected, so long will our patient be subjected to ultimate danger. The more I investi gate the subject and the more I see of the treatment of cancer in general, the more convinced I become that there is only one rational method of dealing with cancer of the larynx. Early total extirpation of the organ with its tributary lymphatics and glands, whether the latter be apparently diseased or not, is the only possible safeguard against recurrence or metastasis. By no othar method can we give the patient a reasonable assurance of a permanent lease on life. The surgeon who is abreast of the times does not trifle with cancer in other organs. Why should the larynx be made the exception to the rule? We will have to learn the same lesson here that we are slowly learning in the case of cancer in other parts of the body. No one at the present day thinks of taking out half a breast, half a uterus or half a kidney for cancer, no matter how circumscribed the growth may be. It is impossible by inspection either with the laryngoscope or after preliminary division of the thyroid, by transillumination or by the sense of touch, to limit the extent of the disease before operation. As I have demonstrated, even after removal of the larynx the disease may be apparent in one side of the organ and not in the other, and yet the microscope show extensive cancerous deposit in the seemingly normal side. This condition is liable to occur in cases in which the epithelioma originates in the deep-seated glands and may not approach the surface until a late stage of the disease. It is also possible that in a more or less advanced stage of cancer of the larynx or even in its early history we may find young cells in the neighboring lymphatics, as Halsted has demonstrated in the case of cancer of the breast. In the presence, therefore, of the fact that it is impossible to limit the disease by inspection and the sense of touch and in the light of the revelations of the microscope it becomes a serious question whether we accomplish any lasting good by any operation short of complete excision of the larynx and the neighboring lymphatics and glands. Certainly if the disease approaches the middle line, the imperative necessity of complete removal must be apparent to the most timid and doubting operator. Confronted by this uncertainty, the position of the surgeon is a most responsible one. Operations of this class should only be undertaken by surgeons of acknowledged skill and experience and with a conscientious recognition of the ethical relations of operator and patient. Thyrotomy with partial removal of the larynx is not up to date surgery, and is a reversion to and res. surrection of a method of procedure that was discredited and abandoned half a century ago.

Beside the question of life-saving, all other considerations pale into insignificance. Given a cancer confined to the larynx (even through the entire interior of that organ be involved) in a person in fairly good condition, and offering no absolute contra-indication to operation, I would no more hesitate to recommend excision of the larynx and lymphatics than I would under similar circumstances hesitate to recommend excision of the hreast. The conditions surrounding the two operations may bit dissimilar and the danger greater in the one than in the other, but to the patient it is the choice between danger and death.

A great deal has been said in recent years about the dangers of thyrotomy and we are told that we must not operate if the lymphatic glands of the neck be involved. The so called dangers of thyrotomy are largely fanciful. If there be any chance of saving life, I believe a preliminary thyrotomy justifiable, even in the presence of external glandular enlargement, provided such involvement be not, on its face, too extensive. More than that, if, on thorough exposure of the parts assuming that there be no serious contra-indication to operation -it be found that the disease can be thoroughly eradicated, even if such eradication should involve more or less deep dissection of the tissues of the neck, it is far better to give the patient that chance of life than to allow him to drift on to certain and possible death.

Dr. RICHARDSON-The extirpation of a larynx containing a growth which has been proved microscopically to be carcinomatous is as justifiable an operation as can be done in the range of surgery. The operation should be done early. It is impossible, from a laryngoscopic examination, to judge of the extent and character of the growth. We get such a foreshortened image that nothing can be ascertained except perhaps the fact of the malignancy of the growth. Operations short of total extirpation are worse than useless. Where tissue of a malignant nature still exists it is sure to lead to a fatal termination of the case. The radical operation is one which can be executed with considerable ease, and can be made almost a blood ess procedure unless some of the veins are severed; and is not attended with any marked degree of shock. The danger and difficulty .lie in the post-operative stage, until the wound is healed. It is during this period that most of the cases succumb.

Dr. Cohen's plan of doing the preliminary tracheotomy ten or twelve days in advance is well advised. The tendency with many is to do the extirpation too soon after the tracheotomy. I fear that this was one of the causes of the fatal issue in my case, for I only waited a week, when two would have been bet ter. However, I was forced to go on because of the weakened condition of my patient

Dr. SweEny-I would like to question Dr. Myles in reference to the influence on the nasal secretions.

Dr. Myles - They seem to be in very good condition.

Dr. BRYAN-It seems to me that the patient swallows air and the voice is produced by a vibratory expulsion.

Dr. MAKUEN-Though this man can only whisper, I believe that this whisper is due to the action of the organs of articulation upon the natural column of air. It is clear to my mind that a whisper is not dependent upon the larynx or upon the vocal chords. There are no vibrating surfaces here as in Dr. Cohen's case.

Dr. Girbons-Four years ago I registered the voice of Dr. Cohen's patient on the phonographic cylinder, and a year and a half ago I registered it again and found great improvement. Such a test should be made every six months.

Dr. Mrdes-These cases should be seen promptly by men competent to examine them, and should then be taken to a gen eral surgeon for operation. I prefer a surgeon in most cases, because the operation does not occur frequently enough to keep the laryngologist's hand active, though I should not hesitate to do it myself if necessary.

\title{
REPORT OF TWO CASES OF SUPPURATING MASTOIDITIS.
}

Presented to the Section on Laryngology and Otology at the Fortyeighth Annual Meeting of the Americar Medical Association, at Philadelphia, Pa., June 1-4, 1897.

BY J. H. BRYAN, M.D.

WASHINGTON, D. C.

In presenting the following cases of mastoid disease, it is with the object of demonstrating the evil results that are liable to follow acute suppurations of the middle ear, especially when treated with the indiscriminate application of poultices, and the injudicious use of the Politzer air bag. In spite of the advances that have been made within recent years in the treatment of these affections, and the serious results that are almost sure to follow when these cases are badly treated, we still find physicians using the poultice to cause an abscess of the mastoid region to break externally. It has been my misfortune to have had several of these badly managed cases to treat, 
the histories of two of which are herewith subjoined. I think they are good object lessons and may be a warning to some physicians not to allow their cases to go to the verge of dissolution before operative interference.

Case 1.-Acute suppurating otitis media, suppurating mastoiditis, abscess extending into the deeper tissues of the neck. T. M., white, age 56, was admitted to the Garfield hospital, June 24 , 1896, stating that about six weeks previously he was suddenly seized with a severe pain in the left ear. $\mathrm{He}$ was treated with hot oil applications and poultices and the abscess discharged through the external auditory canal, giving him only slight relief however. The hot applications were continued notwithstanding a large swelling had formed back of the ear, which was excruciatingly painful.

On admission the patient was very much emaciated and weak. His mental faculties were decidedly obtunded, consequently it was not possible to obtain a clear history of his condition, from him. Temperature 100 degrees; pulse 60 . There was a profuse discharge of pus from the external auditory canal, and a large swelling back of the ear, over the mastoid, extending upward toward the temporal region and down into the neck. Slight pressure over the swelling was very painful and caused the pus to flow more freely from the external aud itory canal.

The patient was freely stimulated with whisky and strych nia and the mastoid region shaved and prepared for operation, which was performed June 25, under ether anesthesia. His condition was not considered favorable for anesthesia, but after the use of stimulants he bore that and the operation well. An incision was made commencing just above the auricle and extending down upon the neck about two and a half inches. This was followed by a discharge of a large quantity of pus, which was found to have burrowed in to the deeper tissues of the neck. The cortex of the lower portion of the mastoid was completely destroyed, while the upper portion still remained firm. This was removed with the chisel and rongeur, and the antrum opened; all carious bone was removed with a sharp spoon, and in doing so the lateral sinus was exposed in nearly its full extent. As it was soft to the touch and no evidence of any septic infection, it was not opened. The sloughing tissue in the neck was scraped away with a sharp spoon, and after thoroughly irrigating the wound it was packed with iodoform gauze, and closed with a bandage $; 8 \mathrm{P}$. M. temperature 101 degrees, pulse 120. Owing to the extremely weak condition of the patient he was freely stimulated with whisky.

June 26,8 A. M. temperature was 98.4 degrees, pulse $96 ; 8$ P. M. temperature 100 degrees, pulse 96, and stronger. Other wise doing well.

June 27, 8 A, м. temperature 98.4 degrees, pulse 84. The wound was dressed, owing to the dressings being quite moist. In the neck wound there was still considerable sloughing tissue, which was removed. A continuous flow of pus was still observed coming from the external auditory canal.

June 30 , temperature and pulse normal. Condition of the mastoid and neck wound very much improved. Large pieces of sloughing tissue removed from the lower portion of the wound. Pus continues to discharge freely through the external auditory canal, although little is observed in the mastoid antrum. The solutions pass freely from the antrum through the external auditory canal. The wound was dressed every other day on account of the free discharge of pus.

July 15, while the general condition of the patient has improved very much as well as that of the wound, pus still continues to flow through the external auditory canal. The patient was placed under ether, and the roof and posterior wall of the auditory canal were found to be in a state of extensive caries. The auricle was freed from its bony attachments and thrown forward, and the carious superior and posterior walls of the auditory canal removed with a sharp spoon. The auricle was then brought back into position and after irrigating the wound it was packed with iodoform gauze, both through the canal and from without. There was a rise of temperature to 99.8 degrees after this operation, but it fell to normal in a few days.

The general condition of the patient continued to improve, with the exception of a marked cerebra] irritation amounting at times to decided delirium. This lasted about a week or ten days and then ceased.

September 30 , the patient was discharged from the hospital, cured, the wound having closed completely, and with a hear. ing distance of one inch for the watch.

Case 2.-Acute suppurating otitis media, suppurating mastoiditis with a commencing infltration in to the neck.

The patient, a young man 19 years of age, consulted me
Jan. 11, 1897, giving the following history: December 14 he was seized with a severe pain in the left ear following a slight attack of influenza. In a few hours there was a profuse purulent discharge from the auditory canal which gave him temporary relief, the pain returning, however, with increased severity and extending over the temporal and mastoid regions. Poultices were applied and the air douche used. In a fow days a swelling appeared back of the ear, which became in tensely painful on pressure. This form of treatment was continued until I saw him January 11.

His condition then was serious, he being exceedingly weak and emaciated. His temperature was 99 degrees.

On examination, a profuse purulent discharge was observed flowing from the external auditory meatus, but owing to the swelling of the canal no view of the membrana tympani could be obtained. The auricle stood out prominently from the side of the head, and back of it ever the mastoid region there was a large swelling extending into the neck. The parts were red and very sensitive, pitting on pressure. The patient was sent to the Garfield hospital and prepared for operation, which was peformed on the following day. The incision was made commencing just above the auricle, continued over the mastoid and terminating about two inches below the apex in the neck. Pus in large quantities was found at the apex of the mastoid, burrowing into the deeper tissues of the neck, but none was found over the upper portion of the process, the tissues being swollen from edematous infiltrations. After elevating the periosteum the cortex of the process was observed to be firm, and no opening communicating with upper cells or antrum could be found, but a probe passed readily through the large cell found on the under surface of the mastoid apex. The antrum was opened and the cortex removed with a chisel, when the cells of the mastoid were found to be in a state of caries, and the pus instead of breaking through the cortex found its exit into the tissues of the neck through the under surface of the apex where there is a large cell with very thin walls usually found.

After all the diseased tissue was removed with a sharp spoon, the wound was irrigated with a solution of bichlorid of mercury ( 1 to 3000 ), packed with iodoform gauze and closed with bandage.

January 13, the patient is free from pain and feels generally comfortable. At 8 A. M. temperature 99.2 degrees; 4 P. M. 100 degrees.

The wound was dressed on the fourth day and very little secretion observed. The temperature was now normal and remained so during the convalescence of the patient. The subsequent dressings were made every third day; the wound continuing to heal rapidly, he was able to leave the hospital, cured, March 1 , with a hearing distance of five inches for the watch.

While such cases as the above are not unusual in the experience of most aural surgeons, still they are of value in demonstrating to what extreme conditions patients suffering from suppurative inflammations of the middle ear may arrive; especially when over treated with the ever popular poultice, and subjected to the injudicious use of the Politzer air bag, a most valuable instrument when properly employed, but one capable of doing great injury in the hands of the inexperienced, especially when employed in cases of children with hypertrophy of the post-nasal lymphoid tissue.

818,17 th St., N. W.

\section{AN HISTORICAL SKETCH OF THE OPERA.} ATIONS UPON THE MASTOID PROCESS.

Presented to the Section on Laryngology and Otology at the Forty-elghth Annual Meeting of the American Medical Association, held at Philadelphia, June 1-4. 1897.

BY LAUREnCE TURNBULL, M.D., Ph.D.

AURAL SURGEON JETFERSON MEDICAL COLLEGE HOSPITAL. PHILADELPHIA.

It is now 105 years since a Danish surgeon, Berger of Copenhagen, was suffering from non-suppurative inflammation of the tympanum attended with distressing tinnitus aurium and deafness. To relieve this 